\title{
ПОДХОДЫ К СОЗДАНИЮ ОБНОВЛЕННОЙ БИОСТРАТИГРАФИЧЕСКОЙ ОСНОВЫ ДЕЛЕНИЯ КЕЛЛОВЕЯ ПОВОЛЖЬЯ
}

\section{В.Б. Сельцер, В.Ф. Салтыков 1}

Саратовский государственный университет, кафедра геоэкологии

E-mail: geoecologia@info.sgu.ru

Научно-исследовательский институт естественных наук

Саратовского государственного университета,

отделение геологии

E-mail: dekanat@geol.sgu.ru

Происходящая в настоящее время переоценка стратиграфического положения ряда зональных аммонитов привела к пересмотру последовательности аммонитовых зон, особенно в нижнем подъярусе, и увеличению детальности расчленения келловея. Такая работа в основном выполнена для территории Центральной России, а в Поволжье она находится на начальной стадии. В статье приводятся новые данные и известные сведения, на базе которых обсуждаются возможности составления обновленной биостратиграфической основы деления келловея не только по аммонитам, но и по фораминиферам.

Approaches to Creating an Updated Biostratigraphic Base for Dividing the Callovian from the Volga Region

\section{V.B. Seltser, V.F. Saltykov}

Current reestimation of the stratigraphic positions of some zonal ammonites has resulted in revision of the sequence of ammonite zones, particularly in the Lower substage, and in more detailed stage division. The work has been mainly finished for Central Russia. But it is still in the initial stage in the Volga Region. New data is presented in the

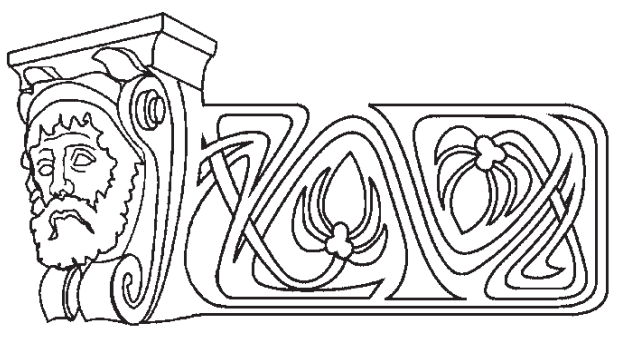

paper. Possibility is discussed of compiling an updated biostratigraphic base for dividing the Callovian not only from ammonites, but from foraminifers, as well.

Благодаря исследованиям В.Г. Камышевой-Елпатьевской с коллегами [1] была создана зональная биостратиграфическая схема расчленения келловея Поволжья. Впоследствии она была несколько модернизирована $[2,3]$ и приведена в соответствие с унифицированной стратиграфической схемой юрских отложений Русской платформы [4]. Известные и вновь полученные фаунистические материалы были суммированы в новом варианте аммонитовой зональности в келловее Русской платформы, сопряженной с существовавшим в то время стандартом (табл. 1) [5]. На этой основе произведено свитное расчленение отложений $[6$, 7], когда местные стратоны соответствовали по объему подъярусам, причем в качестве стратотипа выбран разрез в Малиновом овраге. Не принижая его биостратиграфическую значимость, следует отметить неодинаковую интерпретацию наблюдательных данных в этом обнажении, полученных различными исследователями, что создает некоторую неопределенность при использовании этого разреза в качестве эталона в случае применения в других районах Поволжья. Подробно эта проблема изложена в нашей работе [8].

Биостратиграфическое расчленение келловея Русской платформы (РСШ)

Таблииа 1 и корреляция с Западной Европой (ОСШ) [5]

\begin{tabular}{|c|c|c|c|c|}
\hline \multicolumn{2}{|c|}{ Ярус, подъярус } & Зоны общей стратиграфической миелы & $\begin{array}{r}\text { Подразделени } \\
\text { стратиграф }\end{array}$ & $\begin{array}{l}\text { льной } \\
\text { гелы }\end{array}$ \\
\hline \multirow{2}{*}{\multicolumn{2}{|c|}{ Нижний оксфорд }} & Cardioceras cordatum & Cardiocer & \\
\hline & & Quenstedtoceras mariae & Quenstedt & \\
\hline \multirow{7}{*}{ 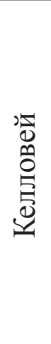 } & \multirow{2}{*}{ Верхний } & Quenstedtoceras lamberti & Quenstedto & erti \\
\hline & & Peltoceras athleta & Peltoce & \\
\hline & \multirow{2}{*}{ Средний } & Erymnoceras coronatum & Erymnocer & \\
\hline & & Kosmoceras jason & Kosmoc & \\
\hline & \multirow{3}{*}{ Нижний } & Sigaloceras calloviense & Sigaloceras calloviense & \multirow{2}{*}{ P. koenigi } \\
\hline & & \multirow{2}{*}{ Macrocephalites macrocephalus } & Cadoceras elatmae & \\
\hline & & & \multicolumn{2}{|c|}{ Слои с Macrocephalites } \\
\hline
\end{tabular}

В течение последних 15 лет происходит переоценка стратиграфического положения ряда зональных аммонитов, а также усложнение их систематики, что привело к пересмотру последовательности аммонитовых зон стандарта и увеличению детальности расчленения келловея. Видимо, этот процесс нельзя считать законченным, особенно применительно к Рус- 
ской платформе. Первой попыткой такого рода являются обстоятельные статьи Дж. Калломона с коллегами $[9,10]$, где рассмотрено положение зоны Macrocephalites macrocephalus в нижнем подъярусе. Авторы показали, что данный вид аммонита часто определялся неточно. На самом деле типовой вид $M$. macrocephalus встречается на более высоком стратиграфическом уровне - в зоне koenigi. Поэтому для самой низкой зоны этого подъяруса предлагается изменить название - вместо macrocephalus называть herveyi.

Прежде чем перейти к изложению материалов в Поволжье, которые в настоящее время еще не суммированы, целесообразно рассмотреть результаты ревизии, проведенной в Центральной России. Современная схема аммонитовой зональности нижнего келловея Русской платформы в сравнении с Англией и Германией иллюстрируется в табл. 2, составленной В.В. Миттой [11]. Несколько ранее опубликована сводка [12], в которой приводятся схемы аммонитовой зональности для суббореальной и средиземноморской (тетической) провинций Европы, которые отличаются друг от друга, хотя и несут некоторые общие черты. Суббореальный стандарт продемонстрирован в табл. 3 .

Таблийа 2

Хроностратиграфическая шкала нижнего келловея Русской платформы и ее корреляция с Западной Европой [11]

\begin{tabular}{|c|c|c|c|c|c|c|c|c|}
\hline \multicolumn{3}{|c|}{ Англия (стандарт) } & \multicolumn{3}{|c|}{ Русская платформа } & \multicolumn{3}{|c|}{ Германия } \\
\hline \multicolumn{2}{|c|}{ Зоны Подзоны } & \multirow{2}{*}{$\begin{array}{c}\text { Фаунистические } \\
\text { горизонты }\end{array}$} & \multicolumn{2}{|c|}{ Зоны\Подзоны } & \multirow{2}{*}{$\begin{array}{c}\text { Фаунистические } \\
\text { горизонты } \\
\text { Enodatum } \gamma \\
\end{array}$} & \multirow{2}{*}{$\begin{array}{c}\text { Фаунистические } \\
\text { горизонты }\end{array}$} & \multicolumn{2}{|c|}{ Зоны \Подзоны } \\
\hline \multirow{5}{*}{ 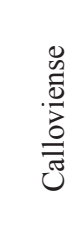 } & \multirow{3}{*}{ End } & & \multirow{5}{*}{. } & \multirow{3}{*}{ End } & & & \multirow{3}{*}{ End } & \multirow{5}{*}{ 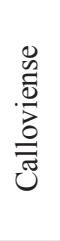 } \\
\hline & & Enodatum $\beta$ & & & Enodatum & \multirow[t]{2}{*}{ Tumidus } & & \\
\hline & & Pagei & & & Pagei & & & \\
\hline & \multirow{2}{*}{ Cal } & Micans & & \multirow{2}{*}{ Cal } & Micans & \multirow{2}{*}{ Calloviense } & \multirow{2}{*}{ Cal } & \\
\hline & & Calloviense & & & Calloviense & & & \\
\hline \multirow{6}{*}{ 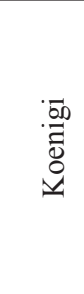 } & Gal & Galilaeii & \multirow{4}{*}{\multicolumn{2}{|c|}{ Gowerianus }} & Galilaeii & ? Galilaeii & \multirow{3}{*}{ Cur } & \multirow{6}{*}{ 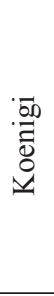 } \\
\hline & \multirow{3}{*}{ Cur } & Trichophorus & & & Indigestus & C-hbotai & & \\
\hline & & Indigestus & & & Curtilobus & Suocostantus & & \\
\hline & & Curtilobus & & & Gowerianus & Macrocephalus & \multirow{3}{*}{ Gow } & \\
\hline & \multirow{2}{*}{ Gow } & Gowerianus & \multirow{9}{*}{ 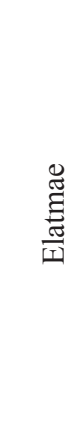 } & \multirow{4}{*}{ Sbp } & Stuckenbergii & Megalocephalus $\beta$ & & \\
\hline & & Metorchus & & & Subpatruus & Megalocephalus $\alpha$ & & \\
\hline \multirow{7}{*}{ 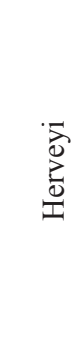 } & \multirow{3}{*}{ Kam } & Kamptus $\gamma$ & & & Surensis & Toricellii & Vom & \multirow{7}{*}{ 交 } \\
\hline & & Kamptus $\beta$ & & & Stupachenkoi & Cf. camptus & Nant & \\
\hline & & Kamptus $\alpha$ & & \multirow{5}{*}{ El } & Tschernyschevi & Suevicum $\beta$ & \multirow{2}{*}{ Ter } & \\
\hline & \multirow{2}{*}{ Ter } & Terebratus $\beta$ & & & Elatmae & Suevicum $\alpha$ & & \\
\hline & & Terebratus $\alpha$ & & & Falsum & Quenstedti & & \\
\hline & $V=$ & Verus & & & Keppleri & Keppleri & Kep & \\
\hline & Nep & Keppleri & & & Bodylevskyi & Keppleri & & \\
\hline
\end{tabular}

Наиболее полно ревизионный подход к биостратиграфии келловея Центральной России отражен в работах В.В. Митты с коллегами [11, 13-18]. Прежде всего следует отметить монографию П.А. Герасимова и др. [14], в которой сначала проводится сравнение стратиграфического расчленения келловея Англии и Русской платформы согласно представлениям различных исследователей (для России - С.В. Мелединой, С.Н. Алексеева и Ю.С. Репина, П.А. Герасимова), затем дается обстоятельный обзор разрезов келловея во многих областях Центральной России с описанием новых видов. Авторы [14] приводят обширный список распределения ископаемых, установленных в пределах келловея с разделением их по подъярусам (губок, мшанок, кораллов, остракод, червей, морских лилий, морских ежей, брахиопод, двустворчатых, брюхоногих и лопатоногих моллюсков, а также белемнитов и аммонитов). Эти данные на новом уровне повторяют сводку [19], в чем и состоит особая ценность данной работы. В ней показаны трудности корреляции разрезов, изученных в центральных районах Русской платформы.

Следующим важным аспектом стратиграфии келловея, уже отмеченным в унифицированной схеме юры [5], является исключение зоны Arcticoceras ishmae из состава нижнего келловея. В статьях С.В. Мелединой с коллегами [20, 21] при изучении разрезов в бассейне Печоры, которые являются, по их мнению, связующими между Сибирью и Западной Европой, показано, что он относится к среднему бату и сопрягается с зонами progracilis и subcontactus стандарта. Нижний 
Сопоставление зональных шкал келловея Нижнего Поволжья,

Таблииза 3 суббореального стандарта и Центральной России

\begin{tabular}{|c|c|c|c|c|c|c|c|c|}
\hline \multirow{2}{*}{ 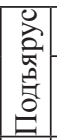 } & \multicolumn{3}{|c|}{ Суббореальный стандарт [12] } & \multicolumn{3}{|c|}{ Центральная Россия [23 - 26] } & \multicolumn{2}{|c|}{ Нижнее Поволжье } \\
\hline & 妥 & Подзона & \begin{tabular}{|c|} 
Фаунистический \\
горизонт \\
\end{tabular} & Подзона & $\begin{array}{r}\text { Фаунис } \\
\text { горı }\end{array}$ & $\begin{array}{l}\text { 1ческий } \\
\text { онт }\end{array}$ & Подзона & $\begin{array}{c}\text { Фаунистический } \\
\text { горизонт }\end{array}$ \\
\hline \multirow{12}{*}{ 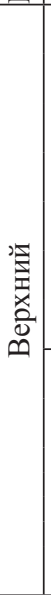 } & \multirow{7}{*}{ 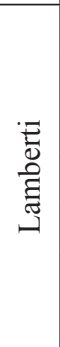 } & \multirow{5}{*}{ Lamberti } & Paucicostatum & \multirow{5}{*}{ Lamberti } & Paucic & statum & \multirow{5}{*}{ Lamberti } & Paucicostatum \\
\hline & & & \multirow{3}{*}{ Lamberti } & & \multirow{2}{*}{\multicolumn{2}{|c|}{ Mojarowski }} & & Angulatum \\
\hline & & & & & & & & Mojarowski \\
\hline & & & & & Lan & erti & & Lamberti \\
\hline & & & Praelamberti & & Praelc & aberti & & Praelamberti \\
\hline & & \multirow{2}{*}{ Henrici } & Henrici & \multirow{2}{*}{ Henrici } & & & \multirow{2}{*}{\multicolumn{2}{|c|}{ Henrici }} \\
\hline & & & Messiaeni & & & & & \\
\hline & \multirow{5}{*}{$\frac{\frac{\pi}{\frac{\pi}{2}}}{\frac{E}{2}}$} & \multirow{3}{*}{ Spinosum } & \multirow[b]{2}{*}{ Spinosum } & \multirow{3}{*}{ Spinosum } & \multicolumn{2}{|c|}{ Kuklium } & \multirow{2}{*}{\multicolumn{2}{|c|}{ Spinosum }} \\
\hline & & & & & \multicolumn{2}{|c|}{ Funiferus } & & \\
\hline & & & & & \multicolumn{2}{|c|}{ Patruum } & \multirow{2}{*}{\multicolumn{2}{|c|}{ Proniae }} \\
\hline & & Proniae & Proniae & Proniae & Allae & ubsp. & & \\
\hline & & Phaeinum & Phaeinum & Phaeinum & Alla & allae & & $?$ \\
\hline & $\Xi$ & Grossouvrei & Grossouvrei & & Gross & uvrei & & \\
\hline & 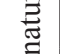 & Urossouvret & Posterior & Grossouvre1 & Pos & rior & & \\
\hline & ర్ & & & & Cra & $\mathrm{um}$ & (?) & ronatum \\
\hline 盗 & & Obductum & Obductum & Obductum & Obd & tum & & \\
\hline ปّ. & & & Jason $\beta$ & & & & Jason & Milaschevici \\
\hline & ₹ & Jason & Jason $\alpha$ & & Jason & & Jason & Jason \\
\hline & $\stackrel{\Xi}{\sim}$ & Meder & Medeo & Medeo & Medea & lagnum & & \\
\hline & & Medea & Medea & Medea & Medes & nedea & & lea (?) \\
\hline & & & Enodatum $\gamma$ & & Enodat & $\mathrm{n}$ aeeta & & \\
\hline & $\begin{array}{l}0 \\
\tilde{c}\end{array}$ & Enodatum & Enodatum $\beta$ & Enodatum & Enodatum & enodatum & Enc & atum (?) \\
\hline & 点 & & Enodatum $\alpha$ & & Enodatum cri & atum (pagei) & & \\
\hline & Uే & Calloviense & Micans & & $\mathrm{Mi}$ & & & \\
\hline & & Canoviense & Calloviense & Calloviense & Callo & iense & & oviense \\
\hline & & Galilaeii & Galilaeii & & & & & \\
\hline & & & Trichophorus & Galilaeii & Gal & aeii & & Tilaeii \\
\hline & .50 & Curtilobus & Tolype & & Curt & obus & & \\
\hline & 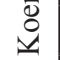 & & Curtilobus & Curtilobus & Indi & stus & & $?$ \\
\hline 丞 & & Goweripnu & Gowerianus & & Gowerianu & & & rianus \\
\hline 荎 & & Gowerianus & Metorchus & & Gowernanus & & & erianus \\
\hline$\Xi$ & & & Kamptus $\gamma$ & & & & & \\
\hline & & Kom & Kamptus $\beta$ & & Croby & oides & & Stuckenbergi \\
\hline & & Kamptus & Kamptus $\alpha$ & & & & Subngtruu & \\
\hline & & & Herveyi & Subpatruus & Uzho & rensis & suopatiuus & \\
\hline & 灰 & & Terebratus $\beta$ & & Subp & truus & & Subpatruus \\
\hline & ? & Terebratus & tereoratus p & & Sur & sis & & \\
\hline & $\pi$ & & Terebratus $\alpha$ & & Tscher & schevi & & Tschernyschevi \\
\hline & & & & & Elatma & elatmae & & \\
\hline & & & verus & & Elatmae & labarense & Elatmae & \\
\hline & & Keppler1 & Keppleri & Elatmae & Primaevum & & & Keppleri/ \\
\hline & & & (jacquoti) & & Poultoni & Jacquot1 & & Bodylevskyi \\
\hline
\end{tabular}


келловей начинается с появления видов Cadoceras elatmae и C. falsum, отнесенных к зоне herveyi стандарта, причем расчленение бата и келловея по аммонитам подтверждается данными по распределению белемнитов и диноцист. Отмечается, что «...зональные виды - C. frearsi (d'Orb.) и Ps. mundum (Sas.) - представляют собой типичные элементы зоны C. elatmae в центральных районах России» [21, с. 30].

Однако существует и несколько иная точка зрения. В своей статье И.И. Сей и Е.Д. Калачёва отмечали: «С границей бата и келловея совпадают крупные тектонические перестройки и начало обширной морской трансгрессии, сопровождавшейся расселением бореальной фауны к югу (бореальное проникновение), что определило палеогеографическую и биогеографическую ситуацию в конце среднеюрской эпохи в бореальных и суббореальных районах нашей страны» [22, с. 47]. Поэтому упомянутые исследователи возражают С.В. Мелединой в том, что касается связующего звена между бореальным и суббореальным келловеем. Они считают, что проблема бат-келловейской границы «...должна рассматриваться раздельно - для Сибири и Русской платформы» [22, с. 50]. И.И. Сей и Е.Д. Калачёва полагали, что «... сибирские С. elatmae отличаются от европейских, имеют более молодой облик и близки к Cadoceras s.s. ...Приводимая C.B. Мелединой зональная последовательность C. falsum - C. elatmae - C. emelianzevi в значительной степени предположительна и не исключает новых кадоцерасовых уровней» [22, с. 50]. Говоря о результатах изучения аммонитов из разреза в Малиновом овраге, И.И. Сей и Е.Д. Калачева указывают, что C. elatmae может «...происходить из зоны S. calloviense, имеет более молодой облик и не может быть отнесен к виду elatmae» [22, с. 51]. Иными словами, его положение в данном разрезе осталось не выясненным. Авторы заключают, что «...на Русской платформе бат-келловейскую границу следует проводить в основании зоны elatmae, объем которой нуждается в уточнении» [22, с. 51].

В обстоятельной работе Д.Б. Гуляева [23] представлены подробные описания разрезов в центральных районах Европейской России и отобранных там аммонитов, сравненных с уточненной аммонитовой зональностью Европы. Важно отметить, что изучены как верхнебатские, так и нижнекелловейские отложения, которые расположены в непосредственном залегании, причем первые сложены в основном алевритами и песками, а вторые - глинами. В низах последних наблюдается небольшое количество песков и песчаных глин. Мощности разновозрастных пород не превышают 15 м, но в разных разрезах они сильно варьируют.

Отобранная богатая фауна позволила Гуляеву выделить ряд биогоризонтов. В состав нижней зоны C. elatmae, соответствующей зоне herveyi стандарта, включены снизу вверх следующие био- горизонты (в скобках указаны подзоны стандарта): M. jacquoti, C. elatmae (keppleri); C. tschernyschevi и частично C. surensis (terebratus); часть последнего, C. subpatruus, Ch. saratovensis (kamptus). К зоне koenigi отнесены биогоризонты K. densicostatus, K. curtilobus, K. trichophorus (аналог гренландской формы K. galilaeii), а к зоне calloviense S. calloviense и $\mathrm{S}$. enodatum.

На рисунке в статье Гуляева [23] изображено вертикальное стратиграфическое распространение родов и подродов, из которого следует, что ряд видов рода Kepplerites (Gowericeras) находятся в зоне koenigi, а некие предковые формы вида $C$. (Rondiceras) milaschevici берут свое начало в зоне calloviense. Необходимо отметить, что упомянутые формы в келловейских отложениях Нижнего Поволжья встречаются достаточно часто. Д.Б. Гуляев высказывает ряд критических замечаний по поводу суждений С.В. Мелединой, Ю.С. Репина, С.Н. Алексеева и Н.Х. Рашвана, касающихся распределения аммонитов в разрезе Малинового оврага. Он подчеркивает: «... интерпретация возраста нижней границы elatmae неоднозначна, нельзя исключить, что она может быть опущена вплоть до нижней части зоны стандартной зоны discus. По-видимому, нижней части зоны elatmae должна также соответствовать зона bodylevskyi Северного Юкона» [23, с. 82]. В то же время отмечается, что «биогоризонт M. јасquoti маркирует нижнюю границу зоны elatmae». Гуляев полагает, что этому уровню соответствует нижняя часть келловея в Малиновом овраге, где обнаружены M. (М.) triangularis (Spath) [24].

Данный исследователь считает, что начало зоны elatmae «соответствует моменту соединения Восточно-Европейского бассейна с морями Тетиса и вступлению его в суббореальную фазу развития» [23, с. 95]. Зона koenigi характеризует этап прогрессивного срастания этого бассейна с морями Западной Европы, который продолжался и в фазу calloviense, когда еще больше возрастает доля низкобореальных и пантетических таксонов в сообществах.

В тезисах своего доклада на международном симпозиуме по юрской системе Д.Б. Гуляев с коллегами [25] представили схему сопоставления биостратиграфических подразделений келловея Северо-Западной Европы, Восточной Гренландии и Европейской России, причем это сделано на уровне вплоть до биогоризонтов. Авторы [25] отмечают близкую корреляцию с суббореальным стандартом от зоны koenigi до конца яруса. Однако корреляция нижнего келловея (зоны elatmae и subpatruus) является только частичной из-за перекрывающего биопровинциализма аммонитов.

Подробный анализ аммонитов из среднего келловея Центральной России выполнил Д.Н.Киселев [26]. Причем он подчеркнул необходимость переописания типовых разрезов в связи с переходом на подзональные и инфраподзональные подразделения. В частности, он переизучил 
классический разрез келловея на р. Оке около г. Елатьмы, а также обнажения у г. Макарьева и вблизи д. Бурдово. Помимо описания вновь обнаруженных видов этот исследователь произвел уточнение стратиграфического положения ранее известных форм, в результате чего представил схему биостратиграфического расчленения среднего келловея Центральной России, куда были включены и материалы из Нижнего Поволжья (из Малинового оврага).

Важно, что обсуждение Д.Н.Киселев выполнил в историческом ракурсе, что позволяет понять первоначальные истоки последующих разногласий при интерпретации фактических данных. Он рассмотрел также граничные горизонты с нижним и верхним подъярусами. Автор дал подробное описание каждого выделенного биогоризонта в зонах enodatum, jason, coronatum, athleta, а в конкретных разрезах привел литологический состав горных пород и характер их залегания в последовательностях. В частности, зона coronatum отделена от нижележащей зоны jason четким перерывом.

Наиболее полный разрез среднего келловея наблюдался в разрезе у г. Елатьмы, где он подразделялся на стандартные подзоны и биогоризонты, которые легко устанавливались по аммонитам. Нижняя граница подъяруса обозначена перерывом в основании зоны enodatum, который выражен как фаунистически, так и литологически. В изученных разрезах почти весь верхний келловей размыт, и выше залегают отложения среднего оксфорда. Следовательно, проблема ярусной границы келловей-оксфорд не решена.

Д.Н.Киселев отмечал, что ряд биогоризонтов на Русской платформе выделяются впервые. Обсуждая границу между нижним и средним келловеем, он предложил изменить стратиграфическое положение подзоны enodatum, которая обладает переходным типом фауны аммонитов, и придать ей статус зоны. Благодаря этому предложению можно снять расхождения между исследователями по поводу границы между подъярусами. Ю.С.Репин и Н.Х.Рашван подчеркивали: «На Русской платформе до сих пор не выявлен разрез, в котором можно было бы проследить непосредственный переход от нижнего к среднему келловею» [24, c. 17]. На существование перерыва между ними указывали многие геологи, изучавшие отложения данного возраста в Поволжье [1-3, 27].

Таким образом, изложенные сведения показывают значительные изменения, внесенные за последние годы в существующую аммонитовую шкалу, принятую в 1993 г. [5], хотя основные черты на уровне подъярусов и отчасти зон сохранились. К сожалению, подобная детальность изученности келловея в Поволжье еще не достигнута, несмотря на то, что здесь имеются как давно известные (Малиновый овраг), так и вновь открытые обнажения, в которых были получены новые и интересные материалы. В частности,
В.Б. Сельцер [28] в Елшанском разрезе около Саратова нашел Kepplerites cf. keppleri (Opp.), Cadoceras cf. bodylevskyi Freb., Costacadoceras sp., характерные для зоны herveуі нижнего келловея. Несмотря на находки аммонита C. elatmae Nik., его положение на площади к югу от широты Саратова до сих пор остается проблематичным, что отмечала еще В.Г.Камышева-Елпатьевская и др.[1]. Но в северных районах Поволжья положение в разрезах этого вида в полной мере соответствует выше приведенным биостратиграфическим схемам, хотя в литературе все же имеются некоторые расхождения.

Следует обратить внимание на публикацию В.В. Митты [13], в которой обсуждается палеонтологическая обоснованность верхней границы келловея в бассейне Волги. Автор считает неправомерным указание на существование перерыва, приходящегося на зону Q. mariae (нижний оксфорд). Он отмечает, что в окрестностях Саратова пограничные отложения келловея и оксфорда представлены полным разрезом (пос. Дубки). Давно известны и другие обнажения на площади восточного склона Приволжской возвышенности, расположенной к северу от Саратова. Они рассмотрены в диссертации В.П. Николаевой (1968 г.), но расчленение отложений произведено на уровне подъярусов.

Выполненный В.Б. Сельцером анализ фаунистических материалов, собранных в Нижнем Поволжье, позволил провести корреляцию зональных шкал келловея в сравнении со стандартом и Центральной Россией (см. табл. 3). За основу составления этой таблицы для Нижнего Поволжья приняты представления В.В. Митты [11, 16-18], хотя они несколько отличаются от результатов работ [23-26]. Однако данные В.В. Митты, на наш взгляд, являются более полными и лучше согласуются с нашими биостратиграфическими сведениями. Исключение сделано для фаунистического горизонта surensis, так как этот вид аммонита не найден в Нижнем Поволжье. Только для верхнего подъяруса фаунистические горизонты (кроме самой нижней зоны phaeinum) можно фактически полно проследить и в Поволжье. Для среднего и нижнего подъяруса с той или иной достоверностью корреляция может быть выполнена на уровне зон, реже подзон, причем обоснованность их в нижнем келловее, как и существование зоны coronatum среднего келловея, до сих пор является спорной. Все это указывает на недостаточную изученность отложений этого возраста в Нижнем Поволжье, тем более что интерпретация данных по стратотипическому разрезу в Малиновом овраге, как показано [8], не является однозначной. С другой стороны, все это свидетельствует о сложном и неравномерном распространении отложений келловея на территории региона. Следовательно, необходимость детальных палеогеографических реконструкций является совершенно очевидной при надежной 
биостратиграфической корреляции выделенных стратонов. Особо следует отметить важность в стратиграфическом отношении указанного выше района около Саратова, так как к югу от него неизвестны самые нижние слои нижнего подъяруса, а в Прикаспии келловей представлен лишь средним и верхним подъярусами. При дополнительном изучении необходимо оценить точное расположение в разрезе аммонита C.elatmae Nik., чтобы установить полноту нижнего подъяруса и определить значимость этой формы при биостратиграфическом расчленении отложений.

В отличие от Центральной России в Поволжье проведены детальные изучения микрофауны, причем в Малиновом овраге эти данные совмещены с распределением аммонитов [29]. Они обсуждались в статье [8]. Традиционно в келловее выделяются фораминиферовые зоны, соответствующие по объемам подъярусам, т. е. они охватывают 2-3 аммонитовые зоны [30]. Но в Прибалтике А.А. Григялис пытался сопоставить каждый фораминиферовый комплекс с одной аммонитовой зоной. Еще в 1961 г. Л.Г. Даин предлагала выделять по два комплекса в нижнем и верхнем келловее [31]. Для первого подразделения это предположение было подтверждено в Донбассе [32] и в Мордовии [33, 34]. Недавно В.Ф.Салтыков [35], основываясь на распределении аммонитов и фораминифер в одних и тех же непрерывных разрезах в скважинах на севере Доно-Медведицких дислокаций, высказал мнение о возможности сопряжения фораминиферовой и аммонитовой зональностей на уровне одной зоны.

Базируясь на этих представлениях предшественников и используя собственные данные, можно привести следующие таксономические составы комплексов (сопутствующие виды не приводятся).

1. Комплекс Reophax scarbrosus - Nodosaria villosa соответствует самой древней зоне herveyi нижнего келловея стандарта (или bodylevskyi - keppleri на Русской платформе). Помимо описанных видов $[33,34] R$. scarbrosus Starts., $N$. villosa Starts., N. costulata Starts., N. insigne Starts., Trochammina pileolae Starts.,сюда включаются Ammodiscus graniferus Kosyr. и единичные формы Haplophragmoides sp.

2. Комплекс H. infracalloviensis - Guttulina tatariensis сопоставляется с аммонитовой зоной koenigi стандарта (зоной gowerianus на Русской платформе). Кроме видов-индексов характерными формами являются: Eoguttulina karlaensis Mjatl., Ammodiscus fontinensis (Terq.), Recurvoides ventosus (Chab.), Marginulina mjarliukae Shakh., $M$. krylovae Mjatl., Dentalina vasta Mjatl., D. plebeja Terq., Lutuotuba nodus Kosyr., Gaudrina sp.

3. Комплекс Lenticulina tatariensis Epistomina callovica сопоставляется с аммонитовой зоной calloviense. Помимо видов-индексов, присутствующих в значительных количествах во многих образцах, характерными видами являются:
L. okrojanzi (Kosyr.), L. praerussiensis Mjatl., L. sphaerica (Kub. et Zw.), L. mira (Kosyr.), L. sculpta (Mitjan.), Ep. poltavica (Kapt.) Pseudolamarckina sp., Astacolus argutus (E.Byk.), Ceratolamarckina tjoplovkaensis Dain. В комплексах 1-2 в основном преобладают агглютинированные раковины, но уже в комплексе 3 значительную роль играют секреционные формы.

4. На границе нижнего и среднего подъярусов наблюдается резкая смена состава микрофауны (в конкретных разрезах она фиксируется в пределах первых метров). Обычно выделяется единая для среднего келловея фораминиферовая зона L. cultratiformis - L. pseudocrassa с лектостратотипом в Малиновом овраге. Однако наши данные дают основания выделять два самостоятельных комплекса, в которых преобладают секреционные формы.

В нижнем, соответствующем аммонитовой зоне jason, видами-индексами являются L.cultratiformis Mjatl. и L. pseudocrassa Mjatl. Они наиболее часто встречаются по разрезу в количестве, превышающем 10 экз. Характерные виды представлены L. cidaris Kosyr., L. ugligi (Wisn.), L. praepolonica K.Kuzn., L. palustris (Mitjan.), L. eichwaldi Grig., L. catascopium (Mitjan.), Astacolus nobilis (Kapt.), As. calloviensis (Mjatl.), Saracenaria gracilis Kosyr., Pseudolamarckina orbiculata Starts., Ps. rjasanensis (Uhlig), Ep. mosquensis (Uhlig), Ep. porcillanea Bruck., Ep. ukrainica Kapt., Ep. dneprica Kapt., Ep. callovica Kapt., Ep. elschankaensis Mjatl.

5. Верхний фораминиферовый комплекс соответствует аммонитовой зоне coronatum. Он характеризуется обедненным таксономическим составом по сравнению с нижним, в котором наблюдается смешение средне- и верхнекелловейских форм. Наиболее обычными видами являются L. cidaris Kosyr., L. tumida Mjatl., L. polonica (Wisn.), Saracenaria gracilis Kosyr., Planularia colligata (Bruck.), Pl. flexuosa (Bruck.), As. batrakiensis (Mjatl.), L. praepolonica K. Kuzn.

6. Обычно для верхнего келловея выделяется единая фораминиферовая зона L. tumida - L. elschankaensis. Однако Г.Н. Старцева и Т.Н. Хабарова [29] в отложениях Малинового оврага различали два комплекса. Для зоны athleta он состоит из L. tumida Mjatl., L. polonica (Wisn.), L. uhligi (Wisn.), Ep. mosquensis (Uhlig), As. batrakiensis (Mjatl.), Saracenaria engelsensis Kosyr., Spirillina kuebleri Mjatl., Verneuilinoides minimus (Kosyr.), Cornuspira variabilis Kub. et Zw., Nubeculinella tenua E. Byk., L. subtilis (Wisn.), L. hoplites (Wisn.), L. praepolonica K. Kuzn., L. subgaleata (Wisn.), L. brevispira (Wisn.), L. simplex (Kub. et Zw.), L. ovatoacuminata (Wisn.), Pl. colligata (Bruck.), Ichyolaria supracalloviensis (Wisn.), Citharinella moelleri (Uglig), C. berthelini (Wisn.), Ep. elschankaensis Mjatl., Pl. tricostata (Mitjan.).

7. Для зоны lamberti приводится состав: $L$. tumida Mjatl., L. polonica (Wisn.), L. uhligi (Wisn.), 
Ep. mosquensis Uhlig, Ep. elschankaensis Mjatl., As. batrakiensis (Mjatl.), Saracenaria engelsensis Kosyr., Spirillina kuebleri Mjatl. Следует отметить определенную неполноту комплекса, так как изучена только нижняя часть зоны, вскрытая в Малиновом овраге.

Рассматривая изложенные сведения в совокупности, можно показать следующие особенности распределения аммонитов и фораминифер по разрезу келловейских отложений.

1. Несмотря на явно недостаточную изученность келловейских аммонитов в Поволжье по сравнению с Центральной Россией, представленная схема сопоставления аммонитовой зональности в разных районах Русской платформы может служить каркасом для обоснования биостратиграфического расчленения келловея в регионе на уровне зон, подзон и фаунистических горизонтов. Однако необходимы дополнительные детальные исследования в обнажениях окрестностей Саратова. Желательно также применять скважинные материалы, позволяющие получить точную привязку органических остатков в пределах полного разреза. В этом отношении возможно использование ранее полученных данных (в частности, диссертацию В.П.Николаевой), но с обязательным переопределением аммонитов. Для келловея данный район может являться одним из немногих, где может быть решена проблема нижней и верхней границ яруса, а также произведено уточнение последовательности биостратиграфических подразделений разного ранга.

2. Подчеркивается стратиграфическая значимость микрофауны, причем отмечается определенная сопряженность аммонитовой и фораминиферовой зональностей на уровне биозон. Представленные данные показывают, что наиболее резкие изменения таксономического состава фораминиферовых комплексов наблюдаются на границе нижнего и среднего келловея. В пределах нижнего подъяруса составы комплексов также существенно различаются, но сопутствующие виды часто являются общими, особенно по мере омоложения отложений. Граница между средним и верхним подъярусами не является четкой, но зона jason значительно отличается от зоны athleta по составу микрофауны. Однако сравнение полных составов фораминиферовых комплексов, особенно с уверенным расположением образцов по разрезу, позволяет получить наглядную картину с учетом применения количественных показателей. Эти соображения свидетельствуют о необходимости комплексного обоснования стратонов при составлении биостратиграфической схемы расчленения келловея в Поволжье.

\section{Библиографический список}

1. Камышева-Елпатьевская В.Г., Николаева В.П., Троuикая E.A. Стратиграфия юрских отложений Саратовс- кого Правобережья по аммонитам // Тр. ВНИГРИ. 1959. Вып.137. С. 3-265.

2. Камымева-Елпатьевская В.Г., Николаева В.П., Троицкая Е.А., Хабарова Т.Н. Келловей юго-востока Русской платформы и его фауна // Вопр. стратиграфии верхней юры. М., 1974. С. 20-28.

3. Николаева В.П., Троицикая Е.А. Фаунистическая характеристика келловея Саратовского и Волгоградского Поволжья // Вопр. стратиграфии и палеонтологии. Саратов, 1975. Вып. 1. С. 42-54.

4. Сазонов Н.T. Унифицированная схема стратиграфии юрских отложений Русской платформы (проект) // Тр. ВНИГНИ. 1961. Вып. 29, т. 2. С. 5-46.

5. Объяснительная записка к унифицированной стратиграфической схеме юрских отложений Русской платформы. СПб., 1993. 72 с.

6. Левина В.И., Прохорова Н.П. Местные стратиграфические подразделения нижней и средней юры Прикаспийского региона // Недра Поволжья и Прикаспия. 2002. Вып. 29. C. 6-13.

7. Олферьев А.Г. Юрские отложения востока Русской платформы // Вопр. совершенствования стратиграфической основы фанерозойских отложений нефтегазоносных регионов России. СПб., 1997. С. 95-107.

8. Салтыков В.Ф., Сельцер В.Б. Анализ изученности опорных разрезов келловея в Поволжье // Изв. Сарат. унта. Нов. сер. Науки о Земле. 2006. Т. 6, вып. 1. С. 79-88.

9. Callomon J. H., Dietl G., Niederhofer H.J. On the true stratigraphic position of Macrocephalites macrocephalus (Schlotheim, 1813) and the nomenclature of the standart Middle Jurassic «macrocephalus zone» // Stuttgart. Beitr. Naturk. 1992. Ser. B. № 185. P. 1-65.

10. Callomon J. H., Wright J.K. Cardioceratid and Kosmoceratid ammonites from the Callovian of Yorkshire // Palaeontology. 1989. V. 32, p. 4. P. 799-836.

11. Митта B.B. О проблемах биостратиграфии средней юры Европейской России // Недра Поволжья и Прикаспия. 2004. Вып. 39. С. 28-33.

12. Biostratigraphie du Jurassique Ouest-Europeen et Mediterraneen. Zonations paralleles et distribution des invertebres et microfossiles / Coord. Cariou E, Hantzperque P. // Bul. Centre Rech. ELF Explor. Prod. 1997. Mem. 17. 440 p.

13. Митта В.B. О пограничных отложениях келловея и оксфорда бассейна Волги // Новости из Геол. музея им. В.И. Вернадского. 2003. № 11. 21 с.

14. Герасимов П.А., Митта В.В., Кочанова М.Д., Тесакова E.M. Ископаемые келловейского яруса Центральной России. М., 1996. 127 с.

15. Митта В.В. Аммониты рода Мacrocephalites в келловее Центральной России // Новости из Геол. музея им. В.И. Вернадского. 1998. № 1.11 с.

16. Митта B.B. Аммониты и биостратиграфия нижнего келловея Русской платформы // Бюл. КФ ВНИГНИ. 2000. № $3.144 \mathrm{c}$.

17. Митта В.В. К эволюции аммонитов и стратиграфии пограничных отложений бата и келловея в бассейне Волги // Экосистемные перестройки и эволюция биосферы. М., 2004. Вып. 6. С. 125-136.

18. Митта В.В., Стародубиева И.А. Полевые работы 1998 г. и биостратиграфия нижнего келловея Русской 
платформы // Новости из Геол. музея им. В.И. Вернадского. 1998. № $2.20 \mathrm{c}$.

19. Сазонова И.Г., Сазонов Н.Т. Палеогеография Русской платформы в юрское и раннемеловое время // Тр. ВНИГНИ. 1967. Т. 62.260 с.

20. Меледина С.В., Захаров В.А. Последовательность аммонитовых зон бата и келловея бассейна р. Печоры - ключевая для зональной корреляции средней юры Сибири со стандартом // Геология и геофизика. 1996. Т. 37, № 2. C. 25-36.

21. Меледина С.В., Ильина В.И., Нальняева Т.И. Параллельные биостратиграфические шкалы бореального бата и келловея Печорского севера как инструмент для межрегиональных корреляций // Стратиграфия. Геол. корреляция 1998. Т. 6, № 3. С. 29-42.

22. Сей И.И., Калачева Е.Д. Граница батского и келловейского ярусов в бореальных и суббореальных районах России // Отечественная геология. 1992. № 10. С. 47-52.

23. Гуляев Д.Б. Инфразональная аммонитовая шкала верхнего бата - нижнего келловея Центральной России // Стратиграфия. Геол. корреляция. 2001. Т. 9, № 1. C. $68-96$

24. Репин Ю.С., Рашван Н.X. Келловейские аммониты Саратовского Поволжья и Мангышлака. СПб., 1996. 256 с.

25. Gulyaev D.B., Kiselev D.N., Rogov M.A. Biostratigraphy of the Upper boreale Bathonian and Callovian of European Russia // VI Inter. Simp. of the Jurassic System. Palermo, 2002. P. 81-82.

26. Киселев Д.Н. Зоны, подзоны и биогоризонты среднего келловея Центральной России //Тр. естественно-геогр. фак. Яросл. гос. пед. ун-та им. К.Д.Ушинского. 2001. Спец. вып. $1.38 \mathrm{c.}$
27. Меледина C.B. Зональное деление келловея Русской платформы // Юрские отложения Русской платформы. Л., 1986. C. 119-129.

28. Сельцер В.Б. Нижняя граница келловейского яруса на территории Нижнего Поволжья // Проблемы геологии Европейской России. Тез докл. Всерос. науч. конф. Саратов, 29-31 октября 2002. Саратов, 2002. С. 45-46.

29. Стариева Г.Н., Хабарова Т.Н. Ульяновско-Саратовский прогиб и северо-западная часть Прикаспийской впадины // Биостратиграфия верхнеюрских отложений по фораминиферам. Вильнюс, 1982. С. 50-61.

30. Григялис А.А., Кузнеиова К.И. Стратиграфическая шкала верхней юры СССР по фораминиферам // Изв. АН СССР. Сер. геол. 1987. № 5. С. 26-37.

31. Даин Л.Г. Значение фораминифер для стратиграфии восточной полосы Русской платформы // Тр. ВНИГНИ. 1961. Вып. 29, т. 3. С. 168-176.

32. Пяткова Д.М. Корреляция верхнеюрских отложений платформенной части Украины с одновозрастными образованиями южных районов СССР по фораминиферам // Стратиграфия и корреляция верхней юры СССР по фораминиферам. М., 1985. С. 91-96.

33. Стариева Г.Н. Детальное расчленение верхнеюрских отложений Среднего Поволжья по данным изучения фораминифер // Юрские отложения Русской платформы. Л., 1986. C. $30-40$.

34. Стариева Г.Н., Козлова В.И. Новые виды фораминифер из нижнего келловея бассейна р. Инсар // Вопр. геологии Ю.Урала и Поволжья: В 2 т. Саратов, 1972. Вып. 8, ч. 1. С. $122-128$.

35. Салтыков В.Ф. Фораминиферовые зоны келловейского яруса в Нижнем Поволжье // ДАН. 2006. Т. 407, № 3. C. $367-371$. 